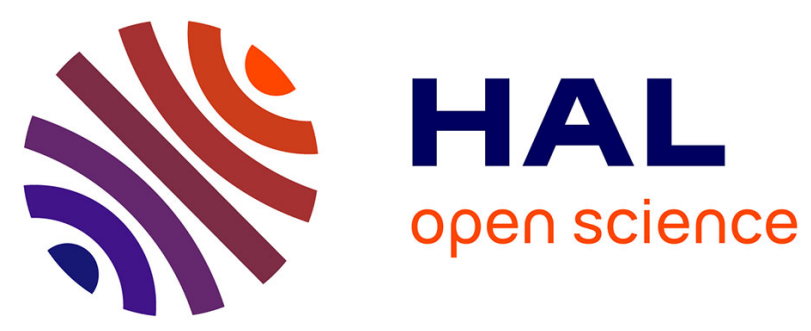

\title{
Combination of sorption properties of polydimethylsiloxane and solid-phase extraction sorbents in a single composite material for passive sampling of polar and apolar pesticides in water
}

\author{
A. Martin, C. Margoum, Marina Coquery, Jerôme Randon
}

\section{To cite this version:}

A. Martin, C. Margoum, Marina Coquery, Jerôme Randon. Combination of sorption properties of polydimethylsiloxane and solid-phase extraction sorbents in a single composite material for passive sampling of polar and apolar pesticides in water. Journal of Separation Science, 2016, 39 (20), pp.39903997. 10.1002/jssc.201600502 . hal-01399907

\section{HAL Id: hal-01399907 https://hal.science/hal-01399907}

Submitted on 21 Nov 2016

HAL is a multi-disciplinary open access archive for the deposit and dissemination of scientific research documents, whether they are published or not. The documents may come from teaching and research institutions in France or abroad, or from public or private research centers.
L'archive ouverte pluridisciplinaire HAL, est destinée au dépôt et à la diffusion de documents scientifiques de niveau recherche, publiés ou non, émanant des établissements d'enseignement et de recherche français ou étrangers, des laboratoires publics ou privés. 


\title{
Combination of sorption properties of polydimethylsiloxane and solid-
}

\section{phase extraction sorbents in a single composite material for passive}

\section{sampling of polar and apolar pesticides in water}

\author{
A. Martin ${ }^{\text {a }}$, C. Margoum* ${ }^{a}$, M. Coquery ${ }^{a}$, J. Randon $^{\mathrm{b}}$ \\ ${ }^{\text {a }}$ Irstea, UR MALY, 5 rue de la Doua, BP 32108, F-69616 Villeurbanne Cedex, France \\ b Univ Lyon, CNRS, Université Claude Bernard Lyon 1, Ens de Lyon, Institut des Sciences \\ Analytiques, UMR 5280, 5 rue de la Doua, F-69100 Villeurbanne, France \\ *Corresponding author: Tel: + 334722087 11; Fax: + 3347847 78 75; Email address: christelle.margoum@irstea.fr
}

\begin{abstract}
Passive sampling techniques have been developed as an alternative method for in situ integrative monitoring of trace levels of neutral pesticides in environmental waters. The objective of this work was to develop a new receiving phase for pesticides with a wide range of polarities in a single step. We describe the development of three new composite silicone rubbers, combining polydimethylsiloxane mechanical and sorption properties with solid-phase extraction sorbents, prepared as a receiving phase for passive sampling. A composite silicone rubber composed of polydimethylsiloxane/poly(divinylbenzene-co- $N$-vinylpyrrolidone) was selected by batch experiments for its high sorption properties for pesticides with octanolwater partition coefficients ranging from 2.3 to 5.5. We named this composite material "Polar/Apolar Composite Silicone Rubber". A structural study by scanning electron microscopy confirmed the homogeneous dispersion of the sorbent particles and the encapsulation of particles within the polydimethylsiloxane matrix. We also demonstrate that this composite material is resistant to common solvents used for the back-extraction of analytes and has a maximal resistance temperature of $350^{\circ} \mathrm{C}$. Therefore, the characteristics of the "Polar/Apolar Composite Silicone Rubber" meet most of the criteria for use as a receiving phase for the passive sampling of pesticides.
\end{abstract}

Keywords: composite material, passive sampling, pesticide, stir bar sorptive extraction, solid-phase extraction 


\section{Introduction}

Passive sampling techniques have been developed as an alternative method for in situ integrative monitoring of various micropollutants in aqueous environments. This technique is well suited for pesticides present at trace levels in environmental waters that have very low environmental quality standards (e.g. $0.03 \mu \mathrm{g} / \mathrm{L}$ for chlorpyrifos-ethyl). Passive samplers contain a receiving phase that accumulates micropollutants by a diffusion process over a set exposure time $[1,2]$. For polar pesticides, the most used receiving phase is typically an SPE sorbent [3].The final mass of pesticides received on SPE sorbents is classically recovered by a simple solvent percolation in one or more steps, before analysis [4].

For hydrophobic micropollutants $\left(3<\log K_{\mathrm{ow}}<10\right)$, polydimethylsiloxane (PDMS), main silicone rubber, was first used in analytical techniques such as SPME [ㄷ], then in stir bar sorptive extraction (SBSE) [] , and later adapted as a receiving phase in sheet, rod or disk form for direct exposure as a passive sampler in environmental waters [7-9]. The PDMS permits the enrichment of hydrophobic organic compounds (polycyclic aromatic hydrocarbons, polychlorinated biphenyls, organochlorine, and organophosphorus pesticides, etc.) with a broad range of polarities $\left(\log K_{\mathrm{ow}}>3\right.$ ) from aqueous solutions [ [8]. The rubbery nature of PDMS confers high mechanical resistance, particularly appreciated in SBSE and in passive sampling applications [8] . PDMS is also insoluble in the common solvents used for analyte back-extraction (methanol and acetonitrile), and it allows thermal desorption at high temperatures $\left(250-300^{\circ} \mathrm{C}\right)[\underline{8,10}]$.

New sample preparation techniques have recently emerged to accumulate polar and apolar compounds. Gilart, Marce, Borrull, and Fontanals [11] have reviewed new coatings for SBSE of polar emerging organic contaminants including recent commercial products. New stir bars are coated with PEG-modified silicone (EG Silicone Twister ${ }^{\circledR}$ ) and polyacrylate with a proportion of PEG (Acrylate Twister ${ }^{\circledR}$ ). In a laboratory test, these two new coatings showed slightly higher extraction recoveries than PDMS for polar compounds such as pharmaceuticals and personal care products [12]. However, owing to their poor mechanical properties compared with PDMS, these coatings must be stabilized by a metal grid to prevent damage and dispersion of the sorbent [13]. Another new material proposed by Barletta et al. [14] was based on the incorporation of activated carbon particles up to $18 \%$ in a PDMS matrix. This composite silicone rubber (CSR) was homogenous, mechanically and chemically stable and seemed suitable for use as a receiving phase. However, when tested for the 
extraction of six pesticides in sugarcane juice samples, extraction recoveries were quite low (<50\%). Other composite materials were also used as SPME coatings, such as the combination of PDMS and a particulate sorbent (with divinylbenzene [ $\underline{5}$ ], graphene oxide [15], poly(divinylbenzene-co- $N$-vinylpyrrolidone) [16]) to improve extraction of polar compounds (haloacetonitriles, haloketones, pesticides, triazoles) in water. However, the use of PDMS as glue for the fixation of particles on the surface [16] generated a vulnerability to erosion and a loss of sorbent particles. To enhance the extraction efficiency of polar pesticides, introducing a polar functional group within the PDMS is clearly an appealing option, but this process is liable to degrade the mechanical properties of PDMS [17]. Hence a compromise between sorption efficiency of polar compounds and mechanical properties has to be sought in the preparation of a new CSR based on PDMS.

The objective of this work was to develop a new receiving phase for the passive sampling of pesticides with a wide range of polarities in a single step. Several new composite silicone rubbers were prepared and tested, combining PDMS with selected SPE sorbents incorporated in different proportions. Batch experiments were performed to select the best CSR based on pesticide extraction recovery. By comparing the selected CSR with PDMS and SPE sorbents, used alone, we then assessed its performance for polar pesticide extraction, and we investigated the dominant sorption mechanism. Finally, the structure and the thermal and chemical stability of the selected CSR were evaluated for its compatibility with backextraction of analytes.

\section{Materials and methods}

\subsection{Chemicals and supplies}

The 22 pesticides selected, including two metabolites, covering a broad polarity range $\left(-0.1<\log K_{\mathrm{ow}}<5.5\right)$ and different chemical structure are listed in Table $\underline{1}$. Pesticides and one internal standard (diuron-d6) were purchased from Dr. Ehrenstorfer (Augsburg, Germany) and Sigma-Aldrich (Saint-Quentin-Fallavier, France). Acetone and dichloromethane for pesticide residue analysis, UHPLC-grade acetonitrile and methanol were purchased from Biosolve (Dieuze, France). Formic acid (purity 98\%) of LC-MS grade was supplied by Waters (Milford, MA, USA). Ultrapure water was obtained using a Millipore water purification system equipped with an LC-Pak cartridge (Billerica, MA, USA). A PDMS Sylgard® 184 kit, composed of a PDMS base including a platinum catalyst and a curing agent (cross-linker) was obtained from Dow Corning (Midland, MI, USA). 
Table 1. List of selected pesticides and LOQ values obtained by UHPLC-MS/MS analysis

\begin{tabular}{|c|c|c|c|}
\hline Pesticide & Abbreviation & $\log K_{\mathrm{ow}}{ }^{\mathrm{a}}$ & $\operatorname{LOQ}\left(\mu \mathrm{g} \mathrm{L}^{-1}\right)^{\mathrm{b}}$ \\
\hline Acetochlor & ATC & 4.1 & 0.40 \\
\hline Atrazine & ATZ & 2.7 & 0.10 \\
\hline Azoxystrobin & AZS & 2.5 & 0.020 \\
\hline Carbendazim & $\mathrm{CBZ}$ & 1.5 & 0.020 \\
\hline Chlorfenvinphos & $\mathrm{CFV}$ & 3.8 & 0.16 \\
\hline Chlorpiryphos-ethyl & $\mathrm{CPE}$ & 4.7 & 0.40 \\
\hline Chlorpiryphos-methyl & CPM & 4.0 & 0.40 \\
\hline Chlortoluron & CTU & 2.5 & 0.40 \\
\hline 3,4-dichloroaniline & DCA & 2.7 & 0.40 \\
\hline $\begin{array}{l}\text { 3-(3,4-dichlorophenyl)-1- } \\
\text { methylurea }\end{array}$ & DCPMU & $2.3 *$ & 0.16 \\
\hline Diflufenican & DFF & 4.2 & 0.40 \\
\hline Diuron & DIU & 2.9 & 0.40 \\
\hline Dimethomorph & DMM & 2.7 & 0.16 \\
\hline Flazasulfuron & FLZ & -0.1 & 0.20 \\
\hline Fenitrothion & FNT & 3.3 & 4.0 \\
\hline Isoproturon & IPU & 2.5 & 0.16 \\
\hline Linuron & LINU & 3.0 & 0.16 \\
\hline Metolachlor & MTC & 3.4 & 0.040 \\
\hline Norflurazon & NFZ & 2.5 & 0.40 \\
\hline Simazine & $\mathrm{SMZ}$ & 2.3 & 0.020 \\
\hline Spiroxamine & SPX & $5.5^{*}$ & 0.16 \\
\hline Tebuconazole & TBZ & 3.7 & 0.16 \\
\hline
\end{tabular}

${ }^{a}$ University of Hertfordshire, Pesticide Properties DataBase: http://sitem.herts.ac.uk/aeru/ppdb/en/atoz.htm

${ }^{\mathrm{b}}$ Limit of quantification determined for direct analysis by UHPLC-MS/MS in Evian ${ }^{\circledR}$ water

* Predicted by ChemAxon: http://www.chemicalize.org/structure

We selected five commercial SPE sorbents, mainly organic copolymers, which contained at least one hydrophobic group to ensure cohesion of PDMS chains, and a hydrophilic moiety. One carbon-based sorbent was also selected for its specific sorption properties [18]. These selected sorbents are widely used in SPE procedures [19]. PDMS was combined with the selected SPE sorbents in particle form: a hydroxylated styrene-divinyl benzene copolymer (ROH-PS-DVB; Evolute® ABN) from Biotage (Uppsala, Sweden), poly(divinylbenzene-co- $N$-vinylpyrrolidone) $\quad$ (PVP-DVB; Oasis ${ }^{\circledR} \quad$ HLB), mixed-mode copolymeric sorbents (quaternary amine functionalized PVP-DVB; Oasis ${ }^{\circ}$ MAX and sulfonated PVP-DVB; Oasis ${ }^{\circledR}$ MCX) from Waters (Mildford, MA, USA) and a porous graphite carbon (PGC; HyperSep Hypercarb ${ }^{\mathrm{TM}}$ ) from Thermo Scientific (Waltham, MA). The PVP-DVB sorbent was available in two particle sizes. More detailed data on the chemical composition and particle properties disclosed by suppliers for these sorbents are listed in the Supporting Information. 


\subsection{Preparation of a composite silicone rubber}

The association of PDMS and selected SPE sorbents in a single CSR was tested according to the following protocol (inspired by Barletta et al. [14]). A mixture of PDMS base and a PDMS curing agent from the Sylgard ${ }^{\circledR} 184$ kit was prepared in a ratio of $10: 1 \mathrm{w} / \mathrm{w}$ according to the suppliers' instructions. A defined particle content (expressed in mass percent fraction) was added to the viscous mixture of PDMS, and was vigorously homogenized by mechanical stirring for $15 \mathrm{~min}$. This mixture was poured into a glass Petri dish (diameter 11 $\mathrm{cm})$, to produce a layer approximately $3 \mathrm{~mm}$ thick. The Petri dish was inserted horizontally in a vacuum chamber $(20 \mathrm{mmHg}$ ) for $60 \mathrm{~min}$ to remove air bubbles from the mixture. It was then placed horizontally in an oven at $100^{\circ} \mathrm{C}$ for $24 \mathrm{~h}$. Heating caused the cross-linking of PDMS polymer chains and the hardening of the composite material as a sheet $3 \mathrm{~mm}$ thick. After a preliminary test, the maximum suitable particle content ensuring a viscous and apparently homogeneous mixture was 9 or $15 \%$ depending on the CSR.

\subsection{Morphology and thermal stability of prepared composite silicone rubbers}

The morphology and surface of CSR and PDMS was studied by SEM. A JCM-5000 NeoScope scanning electron microscope from JEOL (Croissy-sur-Seine, France) at an accelerating voltage of $10 \mathrm{kV}$ was used to characterize CSR.Thermogravimetric analysis (TGA) was carried out to determine the temperature of degradation for SPE sorbent, PDMS and CSR (Supporting Information).

\subsection{Batch experiments to measure sorption properties}

To simplify experimental design and analytical procedures, CSR dimensions were chosen close to those of SBSE. The CSR sheet was carefully cut into rods $20 \times 3 \times 3 \mathrm{~mm}$ with a clean cutter blade. The rods were rinsed three times with a solvent mixture (dichloromethane/methanol, 50:50, v/v) for $15 \mathrm{~min}$ under sonication. They were then gently dried with a lint-free tissue and placed at $70^{\circ} \mathrm{C}$ in an oven for $1 \mathrm{~h}$. To ensure homogeneity and repeatability of experiments, the rods of CSR were selected by weight $(170 \mathrm{mg} \pm 2.5 \%)$.

A first batch experiment was performed to compare extraction recoveries of the tested CSRs for the 22 pesticides studied (Table 1). One rod of each CSR was inserted in a $60 \mathrm{~mL}$ amber glass vial containing $50 \mathrm{~mL}$ of Evian ${ }^{\circledR}$ water spiked with pesticides $(\mathrm{pH}=7.2)$. Acetone content for spiking water was calculated so as not to exceed $0.1 \mathrm{vol} \%$ in the aqueous phase. The initial spiked concentration of each pesticide was adjusted from 25 to $550 \mu \mathrm{g} / \mathrm{L}$. 
Stirring $(450 \mathrm{rpm})$ was done with a glass magnetic stir bar on a Variomag magnetic stirrer purchased from Thermo Scientific (Waltham, MA, USA). The batch experiment lasted $48 \mathrm{~h}$. A water sample was collected at the start and at end of the experiment. One experimental blank without pesticides for each CSR and three control batches without CSR were also performed and sampled as described above.

A second batch experiment was performed to optimize the formulation of the CSR that achieved the best sorption properties during the first experiment, by modifying particle size (30 and $60 \mu \mathrm{m})$ and particle content in the $\operatorname{CSR}(5,9$, and 15\%). Extraction recoveries of the best SPE sorbent were also determined to investigate pesticides sorption mechanisms. The extraction conditions were the same as for the first experiment, except for a longer extraction time $(72 \mathrm{~h})$ and lower pesticide concentrations $(2.5-50 \mu \mathrm{g} / \mathrm{L})$.

Both experiments included three independent batches for each CSR material, at an ambient temperature of $20.5 \pm 1^{\circ} \mathrm{C}$. Mineral water (Evian $\AA$ ) was chosen as it is more representative of environmental waters than ultrapure water. The extraction recovery $(R, \%)$ is expressed as the ratio, in percent, of the difference in concentration of pesticide measured in water at the end of the experiment between the control batch and the CSR batch, to the initial concentration of pesticide measured in water. A complementary desorption experiment was conducted to determine the solvent back-extraction recoveries of the selected CSR (Supporting Information).

\subsection{Sample preparation and analysis by LC}

Water samples were analyzed by direct injection. A volume of $10 \mu \mathrm{L}$ of diuron-d6 (internal standard) at a concentration of $1000 \mu \mathrm{g} / \mathrm{L}$ was added to $990 \mu \mathrm{L}$ of an aliquot of water to obtain a diuron-d6 concentration of $10 \mu \mathrm{g} / \mathrm{L}$.

UHPLC was performed on a Shimadzu series Nexera X2 UHPLC system (Marne-laVallée, France). Analytes were separated on an Acquity UPLC® HSS T3 $1.8 \mu \mathrm{m} 2.1 \times 100$ mm Waters column (Milford, MA, USA). Chromatographic separation of analytes was carried out with acetonitrile and ultrapure water, both with formic acid $(0.1 \%)$ in an analytical gradient (from 10 to $90 \%$ acetonitrile) of $15 \mathrm{~min}$ at $0.6 \mathrm{~mL} / \mathrm{min}$. The UHPLC system was coupled to a triple-quadrupole mass spectrometer (MS/MS) API 4000 from AB Sciex (Les Ulis, France). The electrospray ion source (Turbo-Ionspray from AB Sciex) was set to positive mode at $600^{\circ} \mathrm{C}$. Settings for MS/MS analysis (Supporting Information) are detailed in Margoum et al. [20] with additional pesticides optimized and validated afterwards. 


\section{Results and discussion}

\subsection{Polymerization of composite silicone rubber with different SPE sorbents}

The composite materials PDMS/PGC, PDMS/ABN, and PDMS/MAX were prepared with a maximum proportion of $15 \%$ of SPE sorbent; PDMS/PVP-DVB and PDMS/MCX were made with a maximum proportion of $9 \%$. Particle contents higher than $15 \%$ resulted in non-fluid mixtures. This content is close to that reported by Barletta et al. [14], who used 18\% of activated carbon. As detailed in the Supporting Information, the selected SPE sorbents had ranging particle diameters $(25-65 \mu \mathrm{m})$, with the highest, on average, for PVP-DVB $(51.1 \mu \mathrm{m})$ and MCX $(52.6 \mu \mathrm{m})$. The two CSRs with PVP-DVB and MCX sorbents had the lowest maximal suitable particle contents $(9 \%)$. Thus the maximum suitable proportion of particles seems to be linked to the average particle diameter.

The qualitative method used for analyzing the CSR curing process and for determining cure inhibition was an examination whether the final product (after heating in an oven) was tacky or not [21]. The polymerization of PDMS/PGC, PDMS/ABN, and PDMS/PVP-DVB materials was validated, and sorption properties of these materials were tested afterward in batch experiments. Pictures and SEMs of polymerized CSRs are available in the Supporting Information to visualize dispersion of SPE sorbents in PDMS. At macroscopic and microscopic scales, a homogeneous distribution of particles in the CSRs was observed.

The PDMS/MCX and PDMS/MAX composite materials were rejected because of incomplete curing (presence of viscous residues). Oasis ${ }^{\circledR}$ MCX and Oasis ${ }^{\circledR}$ MAX respectively contained sulfonated and amine groups known to poison platinum catalysts by irreversible formation of complexes, shutting down the polymerization reaction permanently [21]. Other PDMS curing reactions, such as polymerization by condensation, could be tested to circumvent this incompatibility.

\subsection{Comparison of sorption properties of composite silicone rubbers}

The three tested CSRs and PDMS remained stable in a strongly stirred environment; floating particles or other apparent degradation were not detected by weight loss. In batch conditions, no pesticide degradation or adsorption was observed for the control batch during $48 \mathrm{~h}$ of experimentation. Extraction recoveries $(R)$ calculated for each pesticide, associated with SD $(n=3)$, are detailed in Table 2 . 
Table 2. Extraction recoveries $(R, \%)$ of 22 pesticides for PDMS and three CSRs (PDMS/ABN, PDMS/PGC, and two different preparations for PDMS/PVP-DVB), associated with relative standard deviations $(\mathrm{RSD}, \%, n=3)$

\begin{tabular}{|c|c|c|c|c|c|}
\hline \multirow{2}{*}{$\begin{array}{l}\text { Compound } \\
\text { (abbreviation) }\end{array}$} & \multicolumn{5}{|c|}{ CSR (particle proportion) } \\
\hline & PDMS & $\begin{array}{c}\text { PDMS/ABN } \\
(15 \%)\end{array}$ & $\begin{array}{c}\text { PDMS/PGC } \\
(15 \%)\end{array}$ & $\begin{array}{c}\text { PDMS/PVP-DVB } \\
(9 \%, \text { Prep- } 1)\end{array}$ & $\begin{array}{c}\text { PDMS/PVP-DVB } \\
(9 \%, \text { Prep- } 2)\end{array}$ \\
\hline$\overline{\text { Flazasulfuron (FLZ) }}$ & $1(>100)$ & $4(>100)$ & $1(>100)$ & $2(>100)$ & - \\
\hline Carbendazim (CBZ) & $1(>100)$ & $2(88)$ & $3(>100)$ & $3(99)$ & - \\
\hline Simazine (SMZ) & $1(>100)$ & $4(75)$ & $8(48)$ & $26(15)$ & $20(18)$ \\
\hline Norflurazon (NFZ) & $9(31)$ & $17(10)$ & $10(32)$ & $25(14)$ & $25(16)$ \\
\hline Azoxystrobin (AZS) & $12(48)$ & $38(5)$ & $32(23)$ & $65(11)$ & $68(7)$ \\
\hline Chlortoluron (CTU) & $2(>100)$ & $9(25)$ & $12(43)$ & $27(10)$ & $29(16)$ \\
\hline Isoproturon (IPU) & $4(>100)$ & $8(45)$ & $2(>100)$ & $23(12)$ & $25(13)$ \\
\hline Dimethomorph (DMM) & $7(68)$ & $11(50)$ & $6(62)$ & $28(6)$ & $23(17)$ \\
\hline 3,4-dichloroaniline (DCA) & $2(>100)$ & $66(4)$ & $69(8)$ & $92(7)$ & $97(8)$ \\
\hline Atrazine (ATZ) & $2(>100)$ & $16(27)$ & $31(20)$ & $52(4)$ & $47(6)$ \\
\hline Diuron (DIU) & $4(>100)$ & $17(20)$ & $26(15)$ & $41(10)$ & $44(9)$ \\
\hline $\begin{array}{l}\text { 3-(3,4-dichlorophenyl)-1- } \\
\text { methylurea (DCPMU) }\end{array}$ & $3(>100)$ & $13(19)$ & $16(27)$ & $20(15)$ & $19(18)$ \\
\hline Linuron (LINU) & $9(29)$ & $73(3)$ & $78(6)$ & $91(5)$ & $97(5)$ \\
\hline Fenitrothion (FNT) & $55(7)$ & $98(3)$ & $93(3)$ & $93(3)$ & $98(3)$ \\
\hline Metolachlor (MTC) & $25(8)$ & $69(2)$ & $49(13)$ & $87(5)$ & $93(5)$ \\
\hline Tebuconazole (TBZ) & $17(29)$ & $52(6)$ & $67(5)$ & $83(5)$ & $84(5)$ \\
\hline Chlorfenvinphos (CFV) & $77(5)$ & $92(3)$ & $78(7)$ & $85(7)$ & $99(5)$ \\
\hline Chlorpiryphos-methyl (CPM) & $91(8)$ & $98(5)$ & $95(1)$ & $95(1)$ & $100(7)$ \\
\hline Acetochlor (ATC) & $22(17)$ & $76(3)$ & $60(6)$ & $93(4)$ & $95(5)$ \\
\hline Diflufenican (DFF) & $93(6)$ & $95(3)$ & $94(3)$ & $94(3)$ & $100(5)$ \\
\hline Chlorpiryphos-ethyl (CPE) & $97(3)$ & $98(3)$ & $94(1)$ & $94(1)$ & $100(5)$ \\
\hline Spiroxamine (SPX) & $99(5)$ & $89(4)$ & $99(6)$ & $98(6)$ & $100(5)$ \\
\hline
\end{tabular}

Repeatability of extraction recoveries between batches, expressed as RSD, was lower than $30 \%$ for every material tested, considering a minimal $R$ of $15 \%$. For $R$ below $15 \%$, differences in concentrations in water between initial and final conditions resulted in excessive uncertainties in final results (RSD exceeded 30\%). We can thus consider that the two most hydrophilic pesticides studied, FLZ $\left(\log K_{\mathrm{ow}}=-0.1\right)$ and CBZ $\left(\log K_{\mathrm{ow}}=1.5\right)$, were not significantly sorbed in any of the materials studied, including single PDMS.

For some hydrophobic pesticides (CPM, DFF, CPE, and SPX), comparison between materials was not possible because $R$ was close to $100 \%$ (i.e. concentrations close to the limit of quantification in water after $48 \mathrm{~h}$ of experimentation). Thus the comparison of sorption properties of CSRs was evaluated with data of 16 pesticides $\left(2.3<\log K_{\text {ow }}<4.1\right)$ out of 22 . 
The PDMS material had good affinities $(R>15 \%)$ for pesticides with $\log K_{\text {ow }} \geq 3.3$ and high affinities $\left(R>90 \%\right.$ ) for $\log K_{\mathrm{ow}} \geq 4$ (apart from ATC), according to its hydrophobic properties $[\underline{8,22]}$. A similar range of affinity for hydrophobic pesticides was observed for all the CSRs tested, as $R$ values were similar or higher than for PDMS. CSRs had better $R$ values than PDMS for polar compounds $\left(\log K_{\text {ow }} \leq 3\right.$ ) with a mean difference in $R$ of $31 \%$. Four polar pesticides (SMZ, CTU, DCA and ATZ) not sorbed by PDMS were accumulated on CSRs due to specific interactions with SPE sorbents contained in CSRs. Out of all the CSRs tested, PDMS/PVP-DVB had the best sorption properties for 16 pesticides, with a mean increase in $R$ of $43 \%$ compared with PDMS (PDMS/PGC (24\%) and PDMS/ABN (26\%)). This result is consistent with better sorption properties of Oasis® HLB sorbent for neutral compounds such as pesticides than the other SPE sorbents tested [23, 24]. However, the amount of PVP-DVB incorporated in the CSR was lower for PDMS/PVP-DVB than for PDMS/PGC and PDMS/ABN (9 vs. 15\%). This observation emphasizes the good sorption capacity of this material. Moreover, the repeatability of laboratory preparation (Prep-1 and Prep-2) of PDMS/PVP-DVB ensures satisfactory robustness (Table $\underline{2}$ ).

From the results of the comparison of CSR sorption capacities for 16 pesticides, we went on to optimize the formulation of the PDMS/PVP-DVB material that seemed the most promising for sorption of both polar and apolar pesticides ( $R$ from 20 to $100 \%$ for 20 pesticides with $2.3<\log K_{\text {ow }}<5.5$ ). This combination of silicone rubber (PDMS) and PVPDVB in a single material is hereafter named "PACSiR" for "Polar/Apolar Composite Silicone Rubber".

\subsection{Influence of particle size}

The impact of particle size of PVP-DVB on sorption properties and preparation was investigated by comparison of PACSiR with a proportion of $9 \%$ of PVP-DVB with particle diameters of around $30 \mu \mathrm{m}$ and $60 \mu \mathrm{m}$. For this comparison, data for pesticides with $R$ lower than $10 \%$ (FLZ and CBZ) were excluded.

Regarding sorption, extraction recoveries in batch experiments were not significantly different between 30 and $60 \mu \mathrm{m}$ (Student's $t$-test, $n=3, \mathrm{CL}=95 \%$ ) for 20 pesticides ( $p$ > 0.05). The amount of pesticide adsorbed is determined by the specific surface area of the particles, which is defined by the total surface developed in internal porosity. Hence the similar $R$ values observed were explained by the same specific area for the two sizes of particles (Supporting Information). These results are consistent with the theory of adsorption 
of pesticides by PVP-DVB, known to be the main process involved in the uptake of compounds by this sorbent $[\underline{25,26}]$.

Additionally, the preparation of PACSiR was simplified with the use of the lower particle size $(30 \mu \mathrm{m})$. The step of incorporation of particles in viscous mixture of PDMS by mechanical stirring is easier, and the resulting mixture is less viscous. This property simplifies the transfer to a Petri dish. More particles could be incorporated in the PACSiR up to a maximum proportion of $15 \%$ while keeping the rubber properties of the PDMS matrix.

\subsection{Impact of proportion of poly(divinylbenzene-co- $\mathrm{N}$-vinylpyrrolidone)in the "Polar/Apolar Composite Silicone Rubber"}

The impact of PVP-DVB content added to PACSiR was studied by adding 5, 9, and $15 \%$ of particles in the CSR. The CSR with 0\% content was PDMS. The PACSiR 5 and 9\% were prepared with particles of $60 \mu \mathrm{m}$, and PACSiR 15\% was only achieved with $30 \mu \mathrm{m}$ particles. The extraction recovery of pesticides was plotted against PVP-DVB content in PACSiR (Fig. 1).

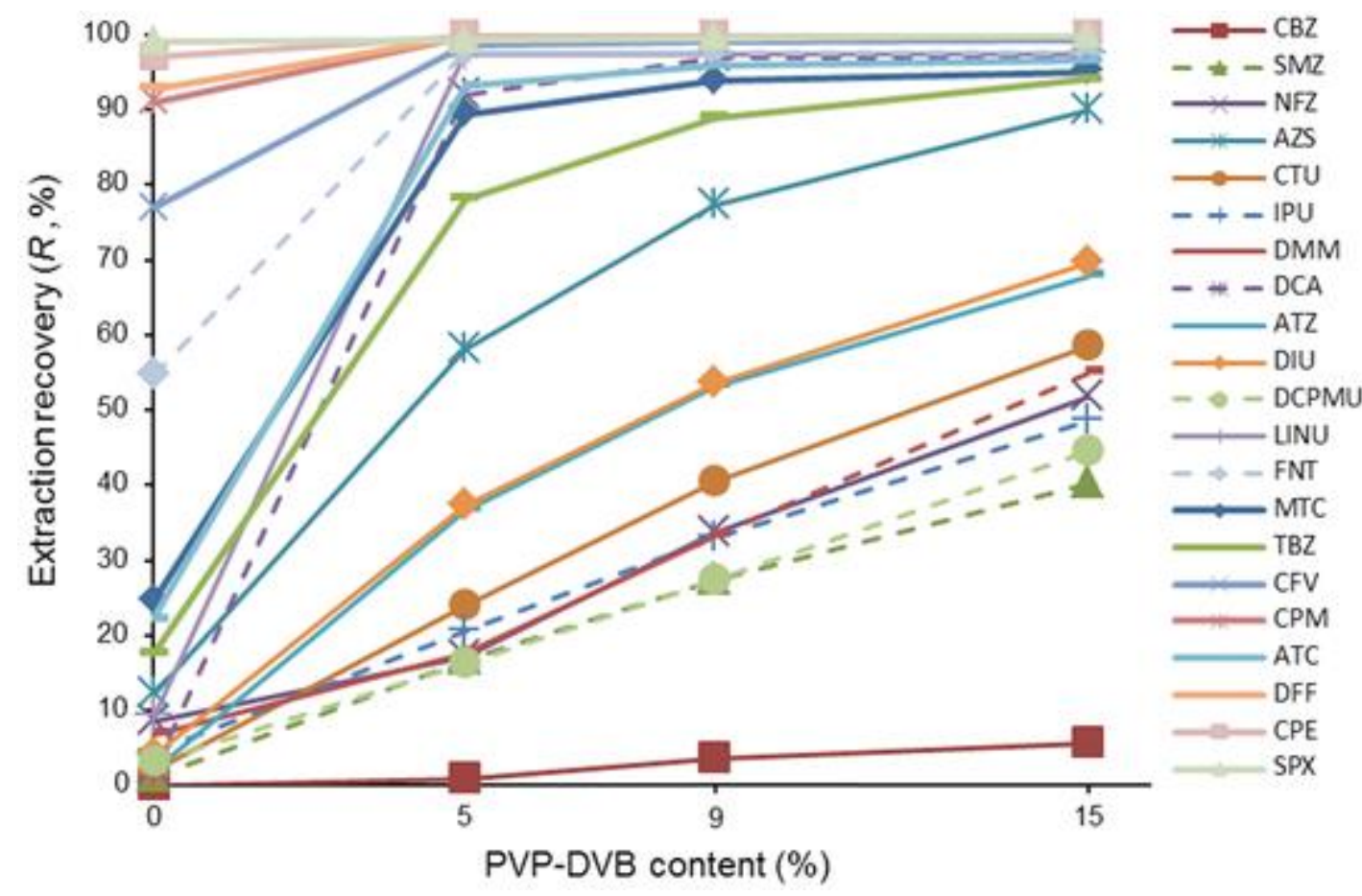

Figure 1. Trend in the extraction recovery of 21 pesticides with increasing proportions of PVP-DVB $(0,5,9$, and $15 \%)$ in CSR.

Overall, $R$ increased with increasing PVP-DVB content. Eight pesticides (SPX, CPE, DFF, CPM, CFV, FNT, LINU, and DCA) were extracted with $R>95 \%$ with only $5 \%$ of PVP-DVB in PACSiR (Fig. 1). SPX, CPE, DFF, CPM, and CFV had high affinity with 
PDMS, with $R>75 \%$ (Table $\underline{2}$ ), and LINU, DCA, and FNT were particularly well sorbed by PVP-DVB.

For other pesticides, $R$ greatly increased with increasing amounts of PVP-DVB in PACSiR. PACSiR 15\% showed the best sorption properties for all the pesticides. For pesticides with low affinity for PDMS $(R<10 \%$; DIU, ATZ, CTU, DMM, NFZ, IPU, DCPMU, SMZ, CBZ), a linear increase was observed $\left(0.93<R^{2}<0.99\right)$ between $R$ and PVPDVB content in PACSiR (excepted for FLZ not sorbed). The mechanism of sorption for these pesticides is mainly adsorption, which is linked to an increase in surface area with the content of sorbent, respectively $6.9,12.4$, and $20.5 \mathrm{~m}^{2}$ for 5,9 , and $15 \%$. By contrast, CBZ was very weakly extracted from water with 5 and $9 \%$ PACSiR $(R=3 \pm 3 \%)$ and had only a slightly higher $R$ value with $15 \% \operatorname{PACSiR}(R=6 \pm 2 \%)$. On the other hand, for four pesticides with medium affinity for PDMS $(10 \%<R<75 \%$; ATC, MTC, TBZ, and AZS), $R$ increased curvilinearly with the particle content. A complementary experiment was carried out to evaluate the dominant sorption mechanism (Supporting Information).

Given the results of these two experiments, we considered that there might be competition in adsorption mechanism between compounds, or the occurrence of two sorption mechanisms (absorption and adsorption) for most of the compounds.

\subsection{Morphological structure of the "Polar/Apolar Composite Silicone Rubber"}

Compared with the smooth surface of single PDMS (Fig. 2 A and B), the surface of PACSiR possessed a granulated structure with no empty cavities in the internal structure of the material (Fig. 2C). An even distribution of PVP-DVB particles was observed in PACSiR by SEM. The SEM image at 540× magnification showed that the particles were not aggregated, and were individually encapsulated by PDMS (Fig. 2D). For particles of larger diameter (SI-5, PACSiR 9\%), aggregates of PVP-DVB particles were observed due to stronger interactions between particles. The use of particles of $30 \mu \mathrm{m}$ is therefore preferred instead of $60 \mu \mathrm{m}$, confirming previous observations. The particles were strongly trapped in the PDMS matrix, no differences in morphology being observed before and after the chemical conditioning step of PACSiR under sonication. Temporary swelling of PDMS by dichloromethane and methanol [27] followed by evaporation of solvent did not affect the structure of PACSiR. The stabilization of PVP-DVB particles within PDMS prevents damage from deterioration in rivers when used as passive sampler. 
Author-produced version of the article published in Journal of Separation Science, (2016) vol. $39, n^{\circ} 20$
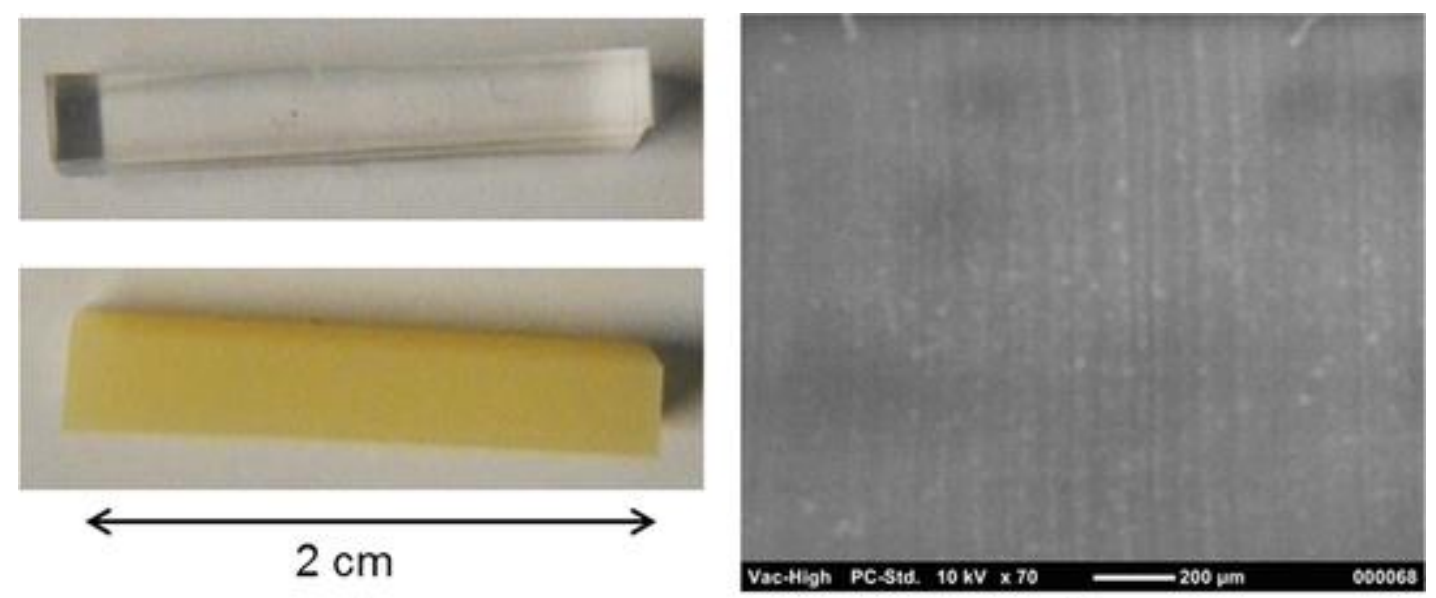

A

B
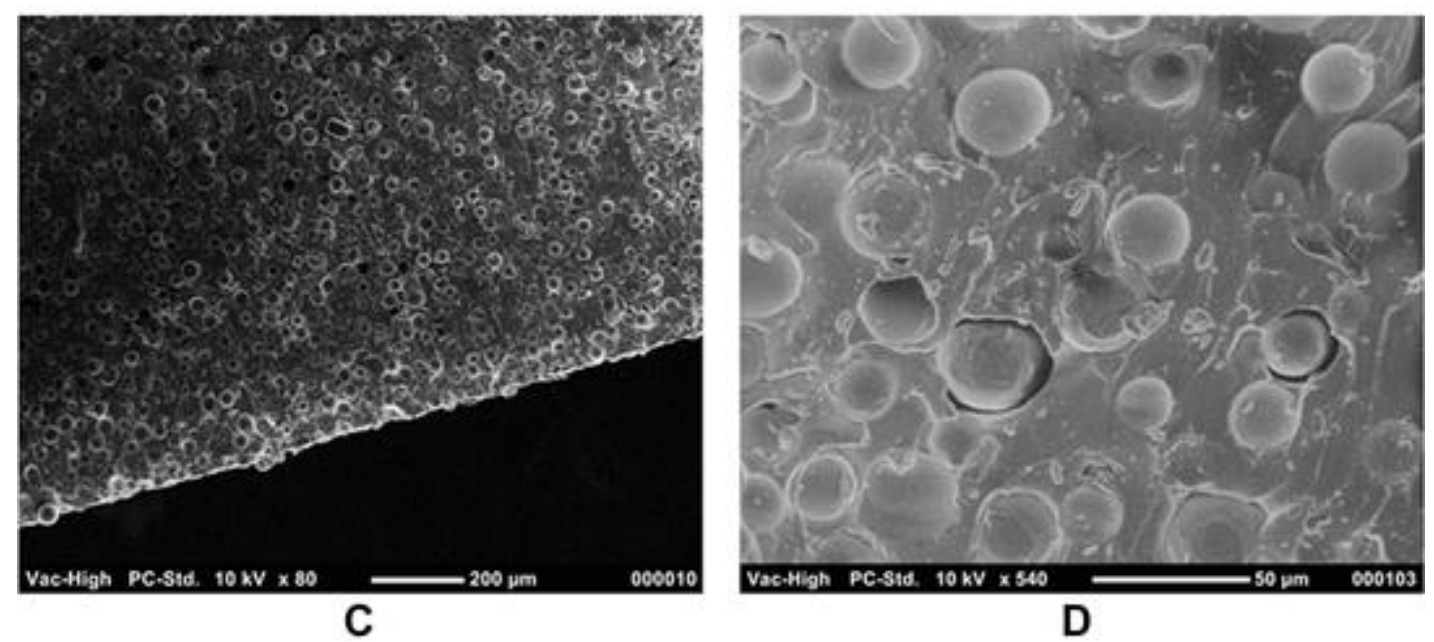

Figure 2. Macroscopic view of (top) PDMS and (bottom) PACSiR (PDMS/PVP-DVB,

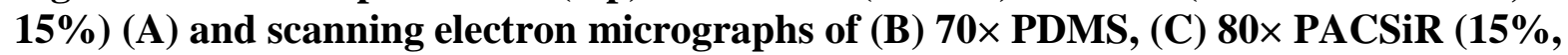
$30 \mu \mathrm{m})$, (D) 540× PACSiR (15\%, $30 \mu \mathrm{m})$.

\section{Concluding remarks}

This work evaluated five SPE sorbents, based on chemical compatibility with PDMS, to make a new CSR. The comparison of sorption properties of three new CSRs for pesticides in batch experiments caused us to select PDMS/PVP-DVB as the best CSR for extraction of a wide range of pesticides. Indeed, extraction recoveries of 11 polar pesticides $\left(2.3<\log K_{\text {ow }}<\right.$ 3.0) ranging from 1 to $12 \%$ with PDMS were improved from 20 to $97 \%$ with PDMS/PVPDVB. This is the first reported instance of sorption properties of PDMS and PVP-DVB being combined in a single CSR mechanically resistant to deterioration. This material was named PACSiR for "Polar/Apolar Composite Silicone Rubber" given its greater affinity for polar and apolar pesticides than PDMS, in the polarity range $2.3<\log K_{\mathrm{ow}}<5.5$. 
A structural study by SEM confirmed the homogeneous dispersion of PVP-DVB particles and the tight encapsulation of particles within the PDMS matrix. We also demonstrated that PACSiR is resistant to common solvents (methanol, acetonitrile and dichloromethane) used for back-extraction of analytes. The thermal stability of PACSiR was linked to that of the PDMS, and a maximum resistance temperature of $350^{\circ} \mathrm{C}$ could be achieved with prior chemical and thermal cleaning steps.

The characteristics of PACSiR meet most of the criteria for use as a receiving phase for passive sampling. The sampling of a wide range of pesticides can thus be done in a single step with a single receiving phase, thereby reducing the cost and time of a pre-concentration step before analysis. It should prove very useful for screening and monitoring pesticides in environmental waters. In a further study, PACSiR will be tested for other classes of compounds such as pharmaceuticals, and for more hydrophobic compounds. The use of PACSiR as an SBSE coating also offers a useful alternative to overcome limitations of PDMS coating for analysis of polar compounds in complex environmental and food matrices.

\section{Acknowledgments}

The authors thank V. Dugas and G. Raffin (ISA, UMR 5280) for SEM analytical support and for TGA analysis and interpretation, respectively. This work was funded by the French National Agency for Water and Aquatic Environments (ONEMA) and the French National Research Agency (ANR) through the PoToMAC project (ANR 2011 CESA 022 02). We thank ATT for English language editing. 


\section{References}

[1] Vrana, B., Mills, G. A., Allan, I. J., Dominiak, E., Svensson K., Knutsson J., Morrison G., Greenwood R., Passive sampling techniques for monitoring pollutants in water. TrAC Trend Anal. Chem. 2005, 24, 845-868.

[2] Seethapathy, S., Gorecki, T., Li, X., Passive sampling in environmental analysis. $J$. Chromatogr. A 2008, 1184, 234-253.

[3] Alvarez, D. A., Petty, J. D., Huckins, J. N., Jones-Lepp, T. L., Getting D.T., Goddard J.P., Manahan S.E., Development of a passive, in situ, integrative sampler for hydrophilic organic contaminants in aquatic environments. Environ. Toxicol. Chem. 2004, 23, 1640-1648.

[4] Andrade-Eiroa, A., Canle, M., Leroy-Cancellieri, V., Cerdà, V., Solid phase extraction of organic compounds: a critical review. TrAC Trend Anal. Chem. 2015, 80, 641-654.

[5] Dugay, J., Miege, C., Hennion, M. C., Effect of the various parameters governing solidphase microextraction for the trace-determination of pesticides in water. J. Chromatogr. A 1998, 795, 27-42.

[6] Baltussen, E., Sandra, P., David, F., Cramers, C., Stir bar sorptive extraction (SBSE), a novel extraction technique for aqueous samples: Theory and principles. J. Microcolumn Sep. 1999, 11, 737-747.

[7] Rusina, T. P., Smedes, F., Koblizkova, M., Klanova, J., Calibration of silicone rubber passive samplers: experimental and modeled relations between sampling rate and compound properties. Environ. Sci. Technol. 2010, 44, 362-367.

[8] van Pinxteren, M., Paschke, A., Popp, P., Silicone rod and silicone tube sorptive extraction. J. Chromatogr. A 2010, 1217, 2589-2598.

[9] Assoumani, A., Margoum, C., Chataing, S., Guillemain, C., Coquery, M., Use of passive stir bar sorptive extraction as a simple integrative sampling technique of pesticides in freshwaters: determination of sampling rates and lag-phases. J. Chromatogr. A 2014, 1333, 18 .

[10] Seethapathy, S., Gorecki, T., Applications of polydimethylsiloxane in analytical chemistry: a review. Anal. Chim. Acta 2012, 750, 48-62.

[11] Gilart, N., Marce, R. M., Borrull, F., Fontanals, N., New coatings for stir-bar sorptive extraction of polar emerging organic contaminants. TrAC Trend Anal. Chem. 2014, 54, 11-23. [12] Gilart, N., Miralles, N., Marce, R. M., Borrull, F., Fontanals, N., Novel coatings for stir bar sorptive extraction to determine pharmaceuticals and personal care products in environmental waters by liquid chromatography and tandem mass spectrometry. Anal. Chim. Acta 2013, 774, 51-60.

[13] Tanwar, S., Di Carro, M., Magi, E., Preconcentration and Determination of 2,6Dichlorobenzamide in Water by Stir Bar Extraction and High-Performance Liquid Chromatography-Tandem Mass Spectrometry. Anal. Lett. 2015, 48, 2288-2302.

[14] Barletta, J. Y., Gomes, P. C., Dos Santos-Neto, A. J., Lancas, F. M., Development of a new stir bar sorptive extraction coating and its application for the determination of six pesticides in sugarcane juice. J. Sep. Sci. 2011, 34, 1317-1325.

[15] Li, Z., Ma, R., Zhang, G., Zhang, S., Wang C., Wu Q., Wang Z., Application of a solidphase microextraction fiber coated with graphene oxide-poly(dimethylsiloxane) composite for the extraction of triazoles from water. J. Sep. Sci., in press. DOI: 10.1002/jssc. 201600485 [16] Kermani, F. R., Tugulea, A. M., Hnatiw, J., Niri, V. H., Pawliszyn, J., Application of automated solid-phase microextraction to determine haloacetonitriles, haloketones, and chloropicrin in Canadian drinking water. Water Qual. Res. J. Can. 2013, 48, 85-98. [17] Panou, A. I., Papadokostaki, K. G., Tarantili, P. A., Sanopoulou, M., Effect of hydrophilic inclusions on PDMS crosslinking reaction and its interrelation with mechanical and water sorption properties of cured films. Eur. Polym. J. 2013, 49, 1803-1810. 
[18] Asperger, A., Efer, J., Koal, T., Engewald, W., Trace determination of priority pesticides in water by means of high-speed on-line solid-phase extraction-liquid chromatographytandem mass spectrometry using turbulent-flow chromatography columns for enrichment and a short monolithic column for fast liquid chromatographic separation. J. Chromatogr. A 2002, 960, 109-119.

[19] Fontanals, N., Marcé, R. M., Borrull, F., Overview of the novel sorbents available in solid-phase extraction to improve the capacity and selectivity of analytical determinations. Contrib. Sci. 2010, 6, 199-213.

[20] Margoum, C., Guillemain, C., Yang, X., Coquery, M., Stir bar sorptive extraction coupled to liquid chromatography-tandem mass spectrometry for the determination of pesticides in water samples: method validation and measurement uncertainty. Talanta 2013, $116,1-7$.

[21] Ortiz-Acosta, D., Densmore, C., Sylgard ${ }^{\circledR}$ Cure Inhibition Characterization. Los Alamos National Laboratory 2011. http://www.osti.gov/scitech/biblio/1053123-sylgard-cureinhibition-characterization (last time accessed: June 27, 2016).

[22] Prieto, A., Basauri, O., Rodil, R., Usobiaga, A., Fernandez L.A., Etxebarria N., Zuloaga O., Stir-bar sorptive extraction: A view on method optimisation, novel applications, limitations and potential solutions. J. Chromatogr. A 2010, 1217, 2642-2666.

[23] D'Archivio, A. A., Fanelli, M., Mazzeo, P., Ruggieri, F., Comparison of different sorbents for multiresidue solid-phase extraction of 16 pesticides from groundwater coupled with high-performance liquid chromatography. Talanta 2007, 71, 25-30.

[24] Donato, F. F., Martins, M. L., Munaretto, J. S., Prestes, O. D., Adaime M.B., Zanella R., Development of a Multiresidue Method for Pesticide Analysis in Drinking Water by Solid Phase Extraction and Determination by Gas and Liquid Chromatography with Triple Quadrupole Tandem Mass Spectrometry. J. Braz. Chem. Soc. 2015, 26, 2077-2087. [25] Bauerlein, P. S., Mansell, J. E., Ter Laak, T. L., de Voogt, P., Sorption behavior of charged and neutral polar organic compounds on solid phase extraction materials: which functional group governs sorption?. Environ. Sci. Technol. 2012, 46, 954-961. [26] Dias, N. C., Poole, C. F., Mechanistic study of the sorption properties of OASIS((R)) HLB and its use in solid-phase extraction. Chromatographia 2002, 56, 269-275.

[27] Rusina, T. P., Smedes, F., Klanova, J., Booij, K., Holoubek, I., Polymer selection for passive sampling: a comparison of critical properties. Chemosphere 2007, 68, 1344-1351. 


\section{I.1.1 Supplementary information}

SI-1. Chemical and physical characteristics of the selected SPE sorbents

\begin{tabular}{|c|c|c|c|c|c|c|}
\hline Abbreviation & PGC & $\mathrm{ABN}$ & \multicolumn{2}{|l|}{ PVP-DVB } & MAX & $\mathrm{MCX}$ \\
\hline $\begin{array}{l}\text { Commercial } \\
\text { name }\end{array}$ & $\begin{array}{l}\text { HyperSep } \\
\text { Hypercarb }^{\mathrm{TM}}\end{array}$ & $\begin{array}{l}\text { Evolute }{ }^{\circ} \\
\text { ABN }\end{array}$ & \multicolumn{2}{|c|}{ Oasis® HLB } & Oasis® MAX & $\begin{array}{l}\text { Oasis® } \\
\text { MCX }\end{array}$ \\
\hline $\begin{array}{l}\text { Chemical } \\
\text { abbreviation }\end{array}$ & PGC & ROH-PS-DVB & \multicolumn{2}{|l|}{ PVP-DVB } & $\begin{array}{ll}\text { PVP- } & \text { DVB } \\
\mathrm{R}_{3} \mathrm{~N}^{+} & \\
\end{array}$ & $\begin{array}{l}\text { PVP-DVB- } \\
\mathrm{SO}_{3}^{-}\end{array}$ \\
\hline $\begin{array}{l}\text { Hydrophobic } \\
\text { groups }\end{array}$ & $\begin{array}{l}\text { Porous } \\
\text { graphitic } \\
\text { carbon } \\
\text { (PGC) }\end{array}$ & $\begin{array}{l}\text { (PS) and DVB } \\
\text { (P) }\end{array}$ & $\begin{array}{c}\mathrm{H}_{1}^{\prime \prime} \\
(\mathrm{DVB})\end{array}$ & & DVB & DVB \\
\hline Polar groups & - & $\mathrm{R}-\mathrm{OH}$ & (VP) & & $\mathrm{VP}$ and $\mathrm{R}_{3} \mathrm{~N}^{+}$ & $\begin{array}{l}\mathrm{VP} \\
\mathrm{SO}_{3}^{-}\end{array}$ \\
\hline $\begin{array}{l}\text { Average } \\
\text { particle } \\
\text { diameter a } \\
(\mu \mathrm{m})\end{array}$ & $(30-40)$ & 45 & $\begin{array}{l}51.1 \\
(50-65)\end{array}$ & $\begin{array}{l}28.0 \\
(25-35)\end{array}$ & $\begin{array}{l}30.5 \\
(25-35)\end{array}$ & $\begin{array}{l}52.6 \\
(50-65)\end{array}$ \\
\hline $\begin{array}{l}\text { Specific } \\
\text { surface area } \\
\left(\mathrm{m}^{2} \mathrm{~g}^{-1}\right)\end{array}$ & 133 & 524 & 812 & 804 & 802 & 801 \\
\hline
\end{tabular}




\section{SI-2. Thermal stability of PACSiR}

The use of PACSiR in thermo-desorption applications for back-extraction of analytes in combination with gas chromatography requires thermal stability with negligible loss of residues as PDMS coating used in SBSE. The degradation temperatures of the PACSiR and its individual components were determined by TGA analysis (SI-2-Figure.). Thermal gravimetric analysis (TGA) was carried out to determine the temperature of degradation for SPE sorbent, PDMS and CSR. TGA was performed on TA Instruments Q50 (New Castle, USA) under a helium stream of $45 \mathrm{~mL} \mathrm{~min}^{-1}$ with a temperature ramp of $10{ }^{\circ} \mathrm{C} \mathrm{min}^{-1}$ from 0 to $550{ }^{\circ} \mathrm{C}$. A first weight loss of $1.0 \%$ was recorded from 0 to $200{ }^{\circ} \mathrm{C}$ for PVP-DVB. Some residues present in this commercial product or water were eliminated; no degradation of copolymer was then observed up to $312{ }^{\circ} \mathrm{C}$. For PDMS, a breakdown $(0.2 \%)$ in TGA analysis was recorded at $179{ }^{\circ} \mathrm{C}$, and the weight of PDMS then slightly decreased with temperature. The PDMS contains polymerization residues that are eliminated with an increase in temperature. The thermal resistance of PDMS can be enhanced by eliminating these residues with chemical or thermal conditioning (van Pinxteren et al., 2010). The thermal resistance of the PACSiR was similar to that of the main component (PDMS). A weight decrease of $0.2 \%$ was recorded from 0 to $194{ }^{\circ} \mathrm{C}$.

After PACSiR preparation and solvent rinse, an additional step of thermal conditioning at a maximal resistance temperature of PVP-DVB $\left(\approx 300^{\circ} \mathrm{C}\right)$ was performed. Thermal conditioning of CSR was tested to increase thermal stability. To this end, some rods of CSR were treated in a Gerstel tube conditioner TC (Mülheim a/d Ruhr, Germany) under a nitrogen stream of $75 \mathrm{~mL} \mathrm{~min}{ }^{-1}$ with a temperature ramp of $10{ }^{\circ} \mathrm{C} \min ^{-1}$ to $300{ }^{\circ} \mathrm{C}$ for $1 \mathrm{~h}$. The TGA analysis of conditioned PACSiR showed an extent of the first weight loss $(0.2 \%)$ from $194{ }^{\circ} \mathrm{C}$ to $350{ }^{\circ} \mathrm{C}$. Complementary tests are needed to validate the use of PACSiR in thermodesorption applications, but these first findings highlight the reliability of the thermal 
Author-produced version of the article published in Journal of Separation Science, (2016) vol. $39, n^{\circ} 20$ The original publication is available at http://onlinelibrary.wiley.com/ doi : 10.1002/jssc.201600502

conditioning step for eliminating residuals and increasing the temperature resistance and stability of PACSiR.

SI-2-Figure. TGA analysis of PDMS, PVP-DVB, PACSiR 9\% and PACSiR 9\% with thermal conditioning (TC).

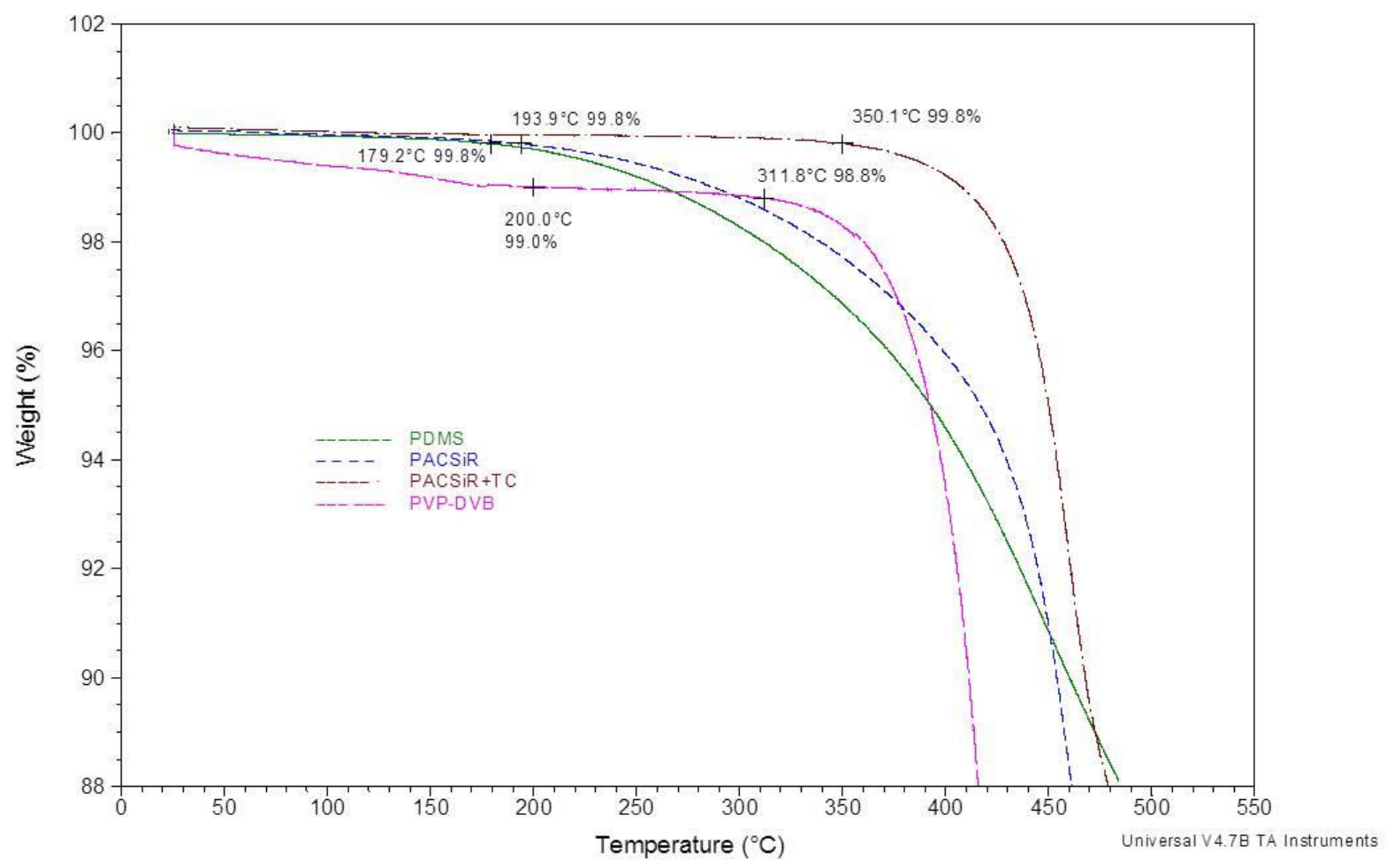




\section{SI-3. Back-extraction of pesticides and compatibility with solvents.}

The use of solvents for back-extraction of pesticides from a solid matrix is widely used for SBSE (Margoum et al., 2013), and is a recommended method for the analysis of polar pesticides sorbed on a receiving phase (Alvarez et al., 2004). To verify the reversibility of sorption, a solvent back-desorption procedure (Margoum et al., 2013) by sonication was applied on PACSiR. Three CSRs were retrieved from the second batch at the end of experiments and stored for at least $24 \mathrm{~h}$ at $-18{ }^{\circ} \mathrm{C}$. Rods of CSR were then desorbed with 200 $\mu \mathrm{L}$ of methanol/acetonitrile $(50: 50, \mathrm{v} / \mathrm{v})$ in a $250 \mu \mathrm{L}$ flat-bottom glass insert under sonication in an ultrasonic bath (FB11014, Fisher Scientific, UK) for 15 min

No apparent loss of particles or swelling of PACSiR was noted under sonication in a methanol/acetonitrile mixture (50:50 v/v), confirming chemical compatibility of PACSiR with these solvents and resistance of the material. Solvent back-extraction recoveries were calculated considering the amount of pesticides sorbed experimentally (SI-3-Figure.). The PACSiR solvent back-extraction recoveries obtained were higher than $60 \%$ for all pesticides (64\% to $129 \%)$, except for SPX $(26 \%)$. We thus demonstrate that sorption by PACSIR is reversible, with a fast and easy solvent back-extraction step. 
Author-produced version of the article published in Journal of Separation Science, (2016) vol. $39, n^{\circ} 20$ The original publication is available at http://onlinelibrary.wiley.com/ doi : 10.1002/jssc.201600502

SI-3-Figure. Mean recovery for 21 pesticides recovered by one solvent back-extraction step (methanol/acetonitrile; 50/50;v/v) with PACSiR (PDMS/PVP-DVB, 15\%, $30 \mu \mathrm{m}$ ) in the second batch experiment $(72 \mathrm{~h})$, with standard deviation $(n=3)$. Pesticides were ranked in ascending order of $\log K_{\text {ow }}$ in brackets.

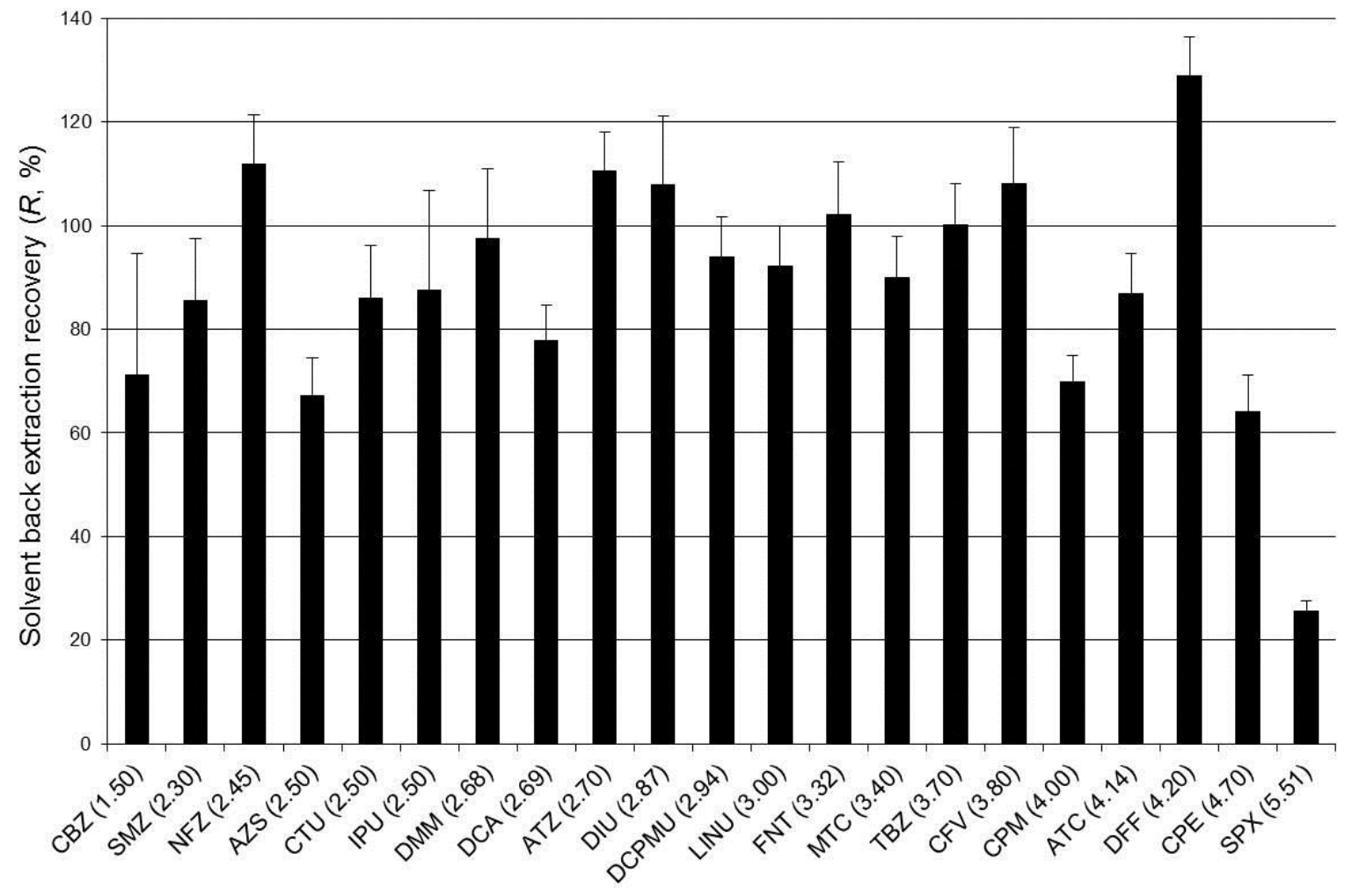


SI-4. Settings for analysis of 22 pesticides and one internal standard by UHPLC-MS/MS.

\begin{tabular}{|c|c|c|c|c|c|}
\hline Pesticide & $\begin{array}{l}\text { Abbre- } \\
\text { viation }\end{array}$ & $\begin{array}{l}\text { Quantification } \\
\text { transition } \\
(\mathrm{m} / \mathrm{z}) \\
\end{array}$ & $\begin{array}{l}\text { Declustering } \\
\text { potential }(\mathrm{V})\end{array}$ & $\begin{array}{l}\text { Collision } \\
\text { energy (V) }\end{array}$ & $\begin{array}{l}\text { Collision exit } \\
\text { potential (V) }\end{array}$ \\
\hline \multirow[t]{2}{*}{ Acetochlor } & \multirow[t]{2}{*}{ ATC } & $269.9>224.2$ & 31 & 15 & 16 \\
\hline & & $269.9>148.1$ & 31 & 27 & 14 \\
\hline \multirow{2}{*}{ Atrazine } & \multirow[t]{2}{*}{ ATZ } & $215.9>174.1$ & 66 & 25 & 16 \\
\hline & & $215.9>104.1$ & 66 & 41 & 8 \\
\hline \multirow[t]{2}{*}{ Azoxystrobin } & \multirow[t]{2}{*}{ AZS } & $404>372$ & 61 & 33 & 26 \\
\hline & & $404>344$ & 61 & 35 & 28 \\
\hline \multirow[t]{2}{*}{ Carbendazim } & \multirow[t]{2}{*}{$\mathrm{CBZ}$} & $192>160$ & 56 & 25 & 16 \\
\hline & & $192>132$ & 56 & 41 & 24 \\
\hline \multirow[t]{2}{*}{ Chlorfenvinphos } & \multirow[t]{2}{*}{$\mathrm{CFV}$} & $359>155$ & 76 & 17 & 20 \\
\hline & & $359>99$ & 76 & 43 & 8 \\
\hline \multirow[t]{2}{*}{ Chlorpiryphos-ethyl } & \multirow[t]{2}{*}{ CPE } & $352>200$ & 45 & 30 & 38 \\
\hline & & $350>97$ & 61 & 55 & 4 \\
\hline \multirow[t]{2}{*}{ Chlorpiryphos-methyl } & \multirow[t]{2}{*}{$\mathrm{CPM}$} & $322>125$ & 71 & 29 & 22 \\
\hline & & $322>290$ & 71 & 23 & 54 \\
\hline \multirow[t]{2}{*}{ Chlortoluron } & \multirow[t]{2}{*}{ CTU } & $213>72$ & 51 & 25 & 12 \\
\hline & & $213>140$ & 51 & 37 & 6 \\
\hline \multirow[t]{2}{*}{ 3,4-dichloroaniline } & \multirow[t]{2}{*}{ DCA } & $162>127$ & 51 & 31 & 24 \\
\hline & & $162>74$ & 51 & 73 & 14 \\
\hline \multirow{2}{*}{$\begin{array}{l}\text { 3-(3,4-dichlorophenyl)-1- } \\
\text { methylurea }\end{array}$} & \multirow[t]{2}{*}{ DCPMU } & $219>162$ & 66 & 21 & 26 \\
\hline & & $219>127$ & 66 & 37 & 22 \\
\hline \multirow[t]{2}{*}{ Diflufenican } & \multirow[t]{2}{*}{ DFF } & $395>266$ & 86 & 35 & 28 \\
\hline & & $395>246$ & 86 & 47 & 40 \\
\hline \multirow{2}{*}{ Diuron } & DIU & $233>72$ & 46 & 51 & 6 \\
\hline & & $233>46$ & 46 & 37 & 8 \\
\hline Diuron-d6 (IS) & DIU-d6 & $239>78$ & 66 & 43 & 14 \\
\hline & & $233>52$ & 66 & 37 & 10 \\
\hline Dimethomorph & DMM & $388>301$ & 76 & 31 & 36 \\
\hline & & $388>165$ & 76 & 43 & 28 \\
\hline Flazasulfuron & FLZ & $408>182$ & 81 & 59 & 34 \\
\hline & & $408>227$ & 81 & 57 & 14 \\
\hline Fenitrothion & FNT & $278>125$ & 71 & 29 & 22 \\
\hline & & $278>109$ & 71 & 25 & 16 \\
\hline Isoproturon & IPU & $207>72$ & 51 & 37 & 8 \\
\hline & & $207>165$ & 51 & 19 & 28 \\
\hline Linuron & LINU & $249>160$ & 61 & 25 & 32 \\
\hline & & $249>182$ & 61 & 19 & 12 \\
\hline Metolachlor & MTC & $284.1>252.2$ & 46 & 21 & 20 \\
\hline & & $284.1>176.2$ & 46 & 37 & 4 \\
\hline Norflurazon & NFZ & $304>284$ & 101 & 35 & 26 \\
\hline & & $304>88$ & 101 & 61 & 16 \\
\hline Simazine & SMZ & $202.1>132.2$ & 56 & 29 & 10 \\
\hline & & $202.1>124.1$ & 56 & 27 & 10 \\
\hline Spiroxamine & SPX & $298>144$ & 51 & 31 & 8 \\
\hline & & $298>100$ & 51 & 45 & 18 \\
\hline Tebuconazole & TBZ & $308>70$ & 76 & 51 & 12 \\
\hline & & $308>125$ & 76 & 57 & 12 \\
\hline
\end{tabular}


Author-produced version of the article published in Journal of Separation Science, (2016) vol. $39, \mathrm{n}^{\circ} 20$ The original publication is available at http://onlinelibrary.wiley.com/

SI-5. Macroscopic view and scanning electron micrographs (SEM) of five materials: PDMS, PDMS/PGC, PDMS/ABN and two PDMS/PVP-DVB.

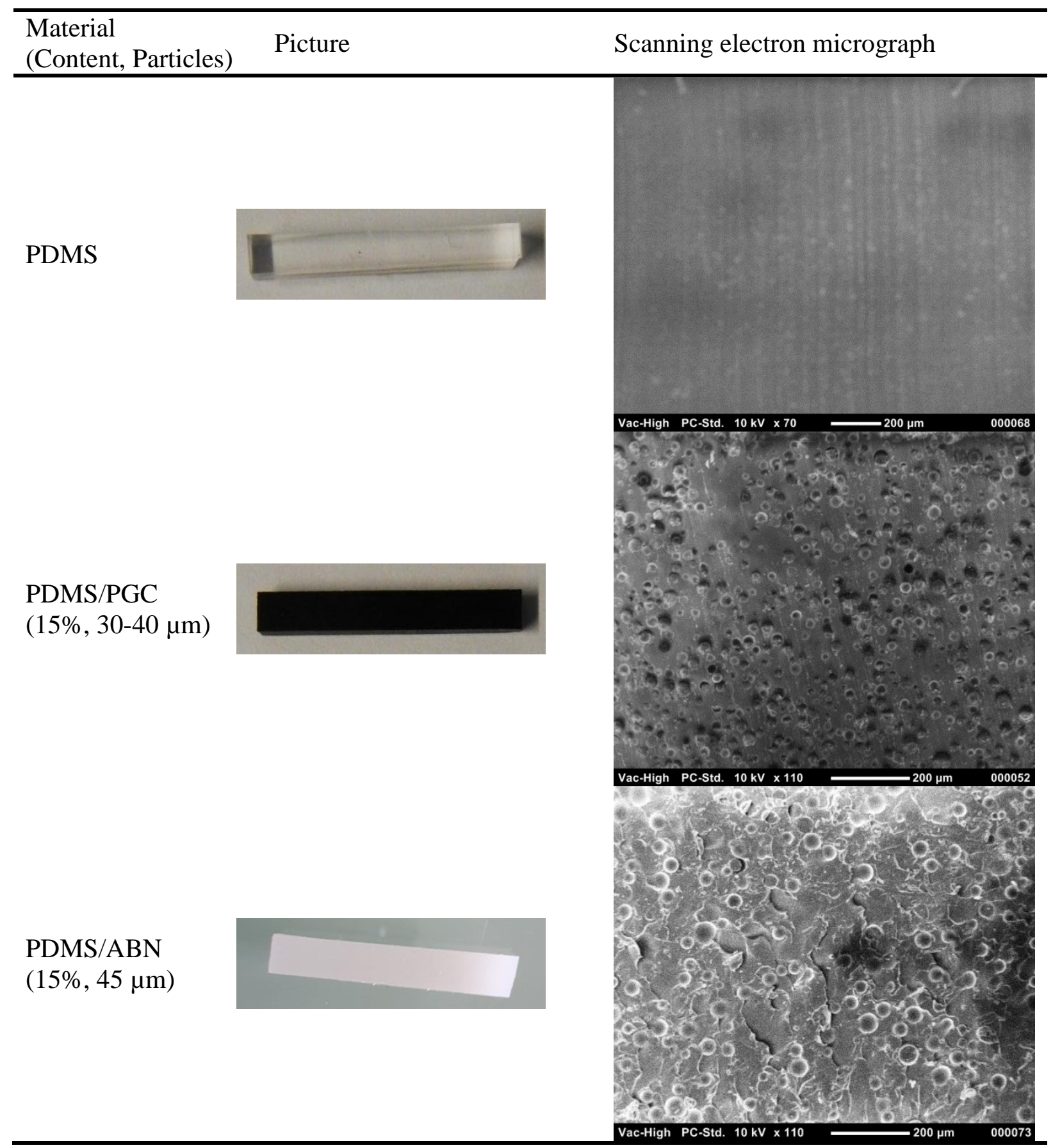


Author-produced version of the article published in Journal of Separation Science, (2016) vol. $39, n^{\circ} 20$ The original publication is available at http://onlinelibrary.wiley.com/ doi : 10.1002/jssc.201600502

PDMS/PVP-

DVB

$(9 \%, 50-65 \mu \mathrm{m})$

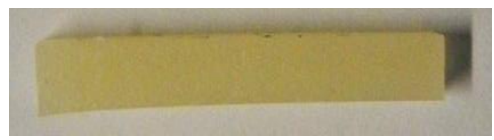

PDMS/PVP-

DVB

$(15 \%, 25-35 \mu \mathrm{m})$

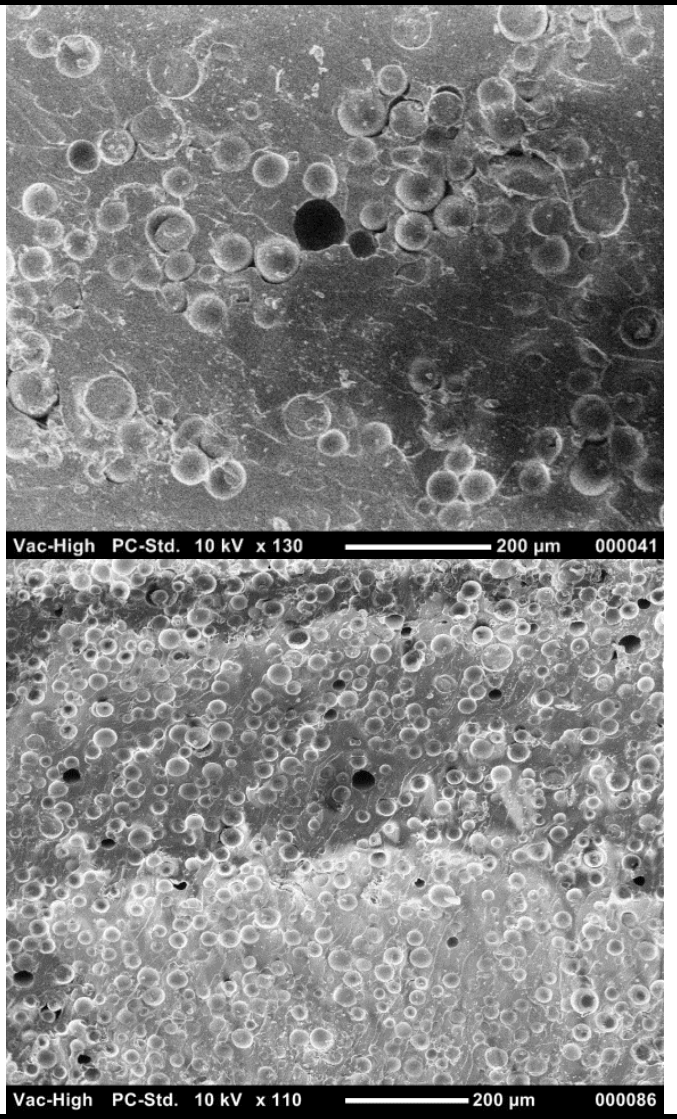


Author-produced version of the article published in Journal of Separation Science, (2016) vol. $39, \mathrm{n}^{\circ} 20$

SI-6. Complementary experiment was carried out to evaluate the dominant sorption mechanism.

The PACSiR 15\% (for a rod of $170 \mathrm{mg}: 25 \mathrm{mg}$ of PVP-DVB and $145 \mathrm{mg}$ PDMS) was compared with an equivalent proportion of particles of PVP-DVB (25 mg) dispersed in a batch experiment (SI-6-Figure.). Extraction recoveries of PDMS (170 mg) are also reported.

For several pesticides (AZS, CTU, IPU, DIU, FNT, MTC, TBZ, and ATC), $R$ values were similar for PACSiR 15\% and PVP-DVB, confirming a dominant adsorption mechanism, without excluding a possible double sorption mechanism. For some pesticides (SMZ, DCA, ATZ, LINU, ATC, and DFF), $R$ increased significantly for PACSiR $15 \%$ compared with single materials (Student's $t$-test, $n=3, \mathrm{CL}=95 \%$ ), demonstrating a possible synergistic effect. For three polar pesticides (NFZ, DMM, and DCPMU), an unknown effect led to a mean decrease in $R$ of $27 \%$ compared with single PVP-DVB. Few differences were found in the sorption of hydrophobic pesticides (CFV, CPM, CPE, and SPX) between PDMS and PVP-DVB. 
SI-6-Figure. Mean extraction recoveries (R) of 22 pesticides for PDMS/PVP-DVB (15\%, 30 $\mu \mathrm{m})$ and for its individual components, PDMS and PVP-DVB. Pesticides are ranked in ascending order of log Kow in parenthesis. Error is expressed as standard deviation ( $\mathrm{n}=3)$.

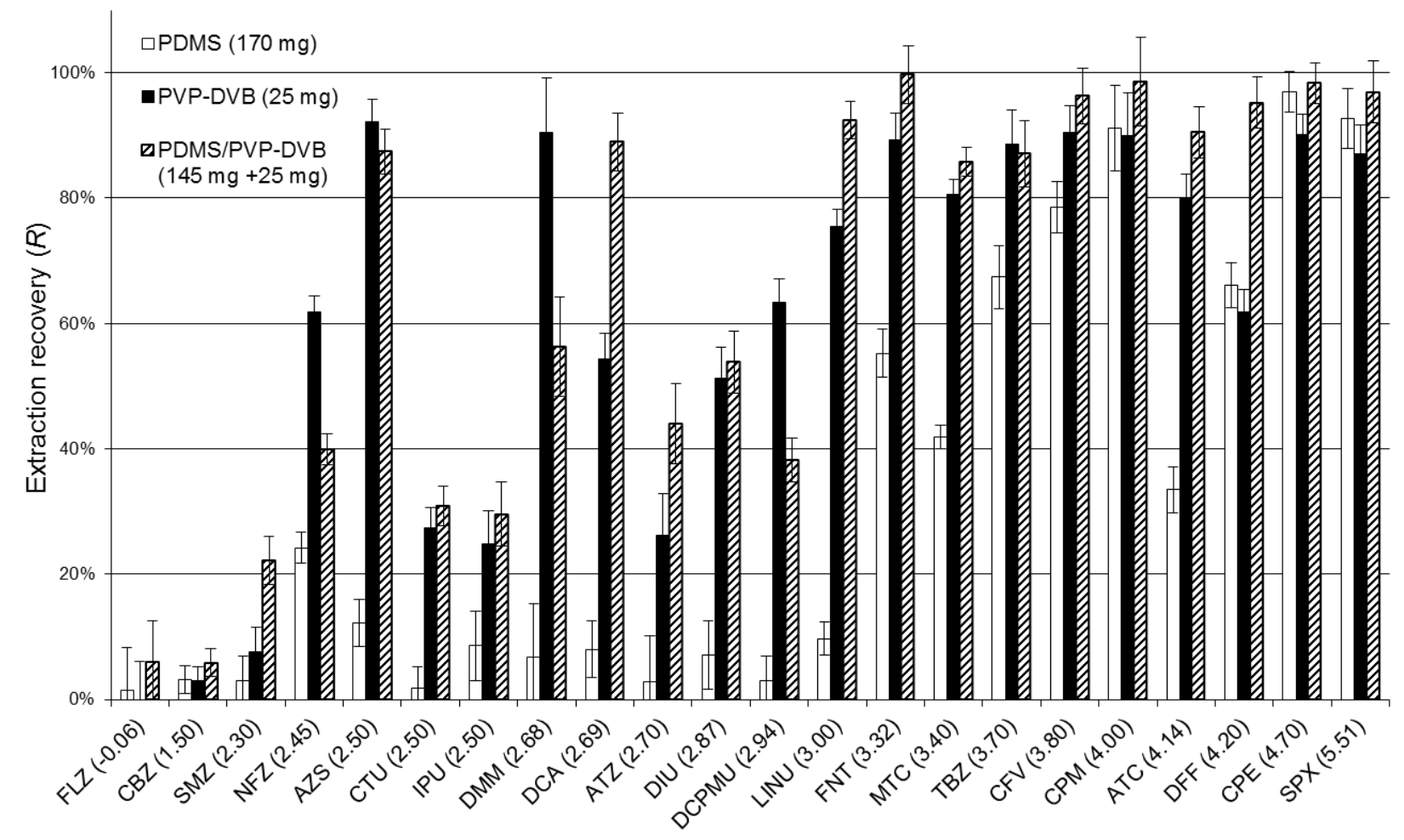

\section{References}

[1] M. van Pinxteren, A. Paschke, P. Popp, J Chromatogr A 1217 (2010) 2589.

[2] C. Margoum, C. Guillemain, X. Yang, M. Coquery, Talanta 116 (2013) 1.

[3] D.A. Alvarez, J.D. Petty, J.N. Huckins, T.L. Jones-Lepp, D.T. Getting, J.P. Goddard, S.E. Manahan, Environ Toxicol Chem 23 (2004) 1640. 
Author-produced version of the article published in Journal of Separation Science, (2016) vol. $39, n^{\circ} 20$ The original publication is available at http://onlinelibrary.wiley.com/ doi : 10.1002/jssc.201600502 